Rabaska

Revue d'ethnologie de l'Amérique française

\title{
GALLAT-MORIN, ÉLISABETH et JEAN-PIERRE PINSON. La Vie musicale en Nouvelle-France. Québec, Septentrion, « Cahiers des Amériques ", 2003, 570 p. ISBN 2-89448-350-3
}

\section{Marie-Hélène Pichette}

Volume 4, 2006

URI : https://id.erudit.org/iderudit/201783ar

DOI : https://doi.org/10.7202/201783ar

Aller au sommaire du numéro

Éditeur(s)

Société québécoise d'ethnologie

ISSN

1703-7433 (imprimé)

1916-7350 (numérique)

Découvrir la revue

Citer ce compte rendu

Pichette, M.-H. (2006). Compte rendu de [GALLAT-MORIN, ÉLISABETH et

JEAN-PIERRE PINSON. La Vie musicale en Nouvelle-France. Québec, Septentrion,

"Cahiers des Amériques », 2003, 570 p. ISBN 2-89448-350-3]. Rabaska, 4,

162-164. https://doi.org/10.7202/201783ar d'utilisation que vous pouvez consulter en ligne.

https://apropos.erudit.org/fr/usagers/politique-dutilisation/ 
Gallat-Morin, Élisabeth et Jean-Pierre Pinson. La Vie musicale en NouvelleFrance. Québec, Septentrion, "Cahiers des Amériques », 2003, 570 p. ISBN 2-89448-350-3.

Publié en 2003, La Vie musicale en Nouvelle-France « établit le bilan le plus complet jamais paru sur la vie musicale en Nouvelle-France » (quatrième de couverture). Dans cet ouvrage, Élisabeth Gallat-Morin, claveciniste et musicologue, et Jean-Pierre Pinson, musicologue et spécialiste de la pratique musicale de l'époque baroque (environ 1600 à 1750), ont voulu combler une lacune. Jusqu'à présent, aucune monographie n'avait traité des pratiques 
musicales de cette époque. Ils ont donc reconstitué la vie musicale à travers la musique qui a survécu et les témoignages provenant majoritairement des sources archivistiques. L'étude commence au début du XVII ${ }^{e}$ siècle, « marqué par l'implantation des institutions [paroissiales, missionnaires (jésuites) et des communautés religieuses] et le développement d'une structure sociale " (p. 17) et se termine en 1800 , avec la parution des premiers livres de plainchant imprimés chez John Nielson à Québec. Les auteurs ont limité leurs recherches à « la vallée du Saint-Laurent qui s'étend depuis les environs de l'actuel Rimouski jusqu'à Montréal en passant par Québec et Trois-Rivières " (pp. 17-18). Pour rendre cette étude encore plus complète, Gallat-Morin et Pinson se sont entourés de quatre collaborateurs. Érich Schwandt, claveciniste, organiste et spécialiste de la musique ancienne, se penche sur le petit motet chez les Ursulines et à l'Hôtel-Dieu de Québec ; Paul-André Dubois, historien et spécialiste du chant religieux en langue amérindienne, parle de la musique chez les Amérindiens et les missionnaires et Conrad Laforte, spécialiste de la chanson folklorique française, traite de la nature de cette chanson en Amérique du Nord ; quant à François Filiatrault, professeur de psychologie au Cégep de Saint-Laurent et collaborateur à la radio de Radio-Canada, il a préparé les documents iconographiques et les encarts biographiques. Depuis sa parution, ce livre a été recommandé par les académiciens de l'Académie des sciences morales et politiques de Paris en plus de remporter un prix Opus, soulignant le dynamisme et la diversité du milieu musical québécois, dans la catégorie « Livre de l'année ».

L'ouvrage se divise en deux parties : la musique religieuse et la musique en société. Dans la première partie, Pinson souligne d'abord que « cette France nouvelle et religieuse devint rapidement une terre de transfert des structures, des pratiques, des chants, des rites, et c'est donc la musique du vieux continent qui fut transportée par-delà l'océan, en admettant au passage quelques adaptations ou enrichissements locaux, sans parvenir à une réelle spécificité » (p. 25). Il fait référence entre autres à la musique figurée des petits motets, mais surtout au plain-chant qui, comme en France, fera un retour au chant grégorien ou cherchera à se réinventer. Les chapitres, parsemés de biographies de personnalités musicales importantes pour l'époque, telles que le flûtiste Jacques Hotteterre ou le compositeur Jean-Baptiste Lully et de nombreux exemples musicaux d'œuvres interprétées en Nouvelle-France, portent sur la messe polyphonique, l'enseignement du chant et la présence de ce dernier dans les cérémonies religieuses des communautés féminines, le rôle important qu'occupera l'orgue dont on a recensé au moins neuf instruments en tout à Québec et à Montréal, le plain-chant et l'implantation du chant liturgique grâce entre autres aux jésuites qui l'intégraient dans toutes leurs célébrations. De plus, l'auteur porte à notre attention l'ambiguité des termes « dire » et 
« chanter ». Selon les sources étudiées, il n'est pas toujours clair si dire et chanter ont réellement des significations distinctes, ce qui a rendu la tâche plus ardue pour déterminer le rôle exact de la musique.

Dans la deuxième partie, Élisabeth Gallat-Morin traite d'abord des activités qui suscitaient une participation musicale telles les danses, les bals, les visites de personnalités importantes, les concerts et les représentations théâtrales, tous ces événements suscitant autant d'intérêt à Québec qu'à Montréal. Ensuite, elle présente les acteurs de cette vie musicale (fonctionnaires, officiers, seigneurs, marchands et musiciens de métier) dont Paul de Chomedey de Maisonneuve, fondateur, premier gouverneur de Ville-Marie et luthiste à ses heures, et Élisabeth Bégon, veuve du gouverneur de TroisRivières, qui en plus de laisser des lettres décrivant en détail les activités musicales à Montréal possédait plusieurs instruments de musique ; elle signale aussi d'autres personnalités qui ont contribué à cette vie musicale soit en collectionnant des livres et des manuscrits, soit en faisant le commerce d'instruments de musique ou en exerçant un métier relié à cet art. Plus loin, l'auteur compare la vie musicale en France et en Nouvelle-France, comparaison intéressante, mais qu'elle juge douteuse à certains égards surtout en considérant les différences de population entre ces deux mondes. GallatMorin en conclut que « du point de vue de la pratique musicale profane, la Nouvelle-France est, en définitive, le miroir de l'Ancienne » (p. 421) et qu'il en est de même pour à peu près tous les autres types de musique. Elle donne en outre un très bref aperçu de la vie musicale en Nouvelle-Angleterre, simplement à titre informatif. Enfin, Conrad Laforte présente la chanson de tradition orale en Amérique française, plus précisément le « répertoire des voyageurs, bien représentatif de la chanson canadienne-française » (p. 428). Une série de douze annexes précisant les pratiques musicales de Québec ou de Montréal et une bibliographie sélective contenant les principales références complètent cet ouvrage important.

Bref, La Vie musicale en Nouvelle-France témoigne efficacement des vingt années de recherche que l'ouvrage a demandé. S'adressant davantage aux musicologues, l'œuvre répond assurément au souhait des auteurs GallatMorin et Pinson, soit de " contribuer à une meilleure compréhension de la musique en Nouvelle-France et montrer que [leur] entreprise en valait la peine » (p. 446). Il s'agit donc d'un ouvrage de référence de grande qualité à recommander fortement aux chercheurs, mais aussi à tous ceux qui douteraient de l'existence d'une vie musicale au Canada français.

Marie-Hélène Pichette

Ottawa 